\title{
Exhibition of Class Ai: A Review
}

\section{Ekin Tutan*}

Exhibited between 21-24 July 2016 at the annual Open Doors - Rundgang at the Universität der Künste Berlin, Hardenbergstrasse 33, Room 91, 10623 Berlin

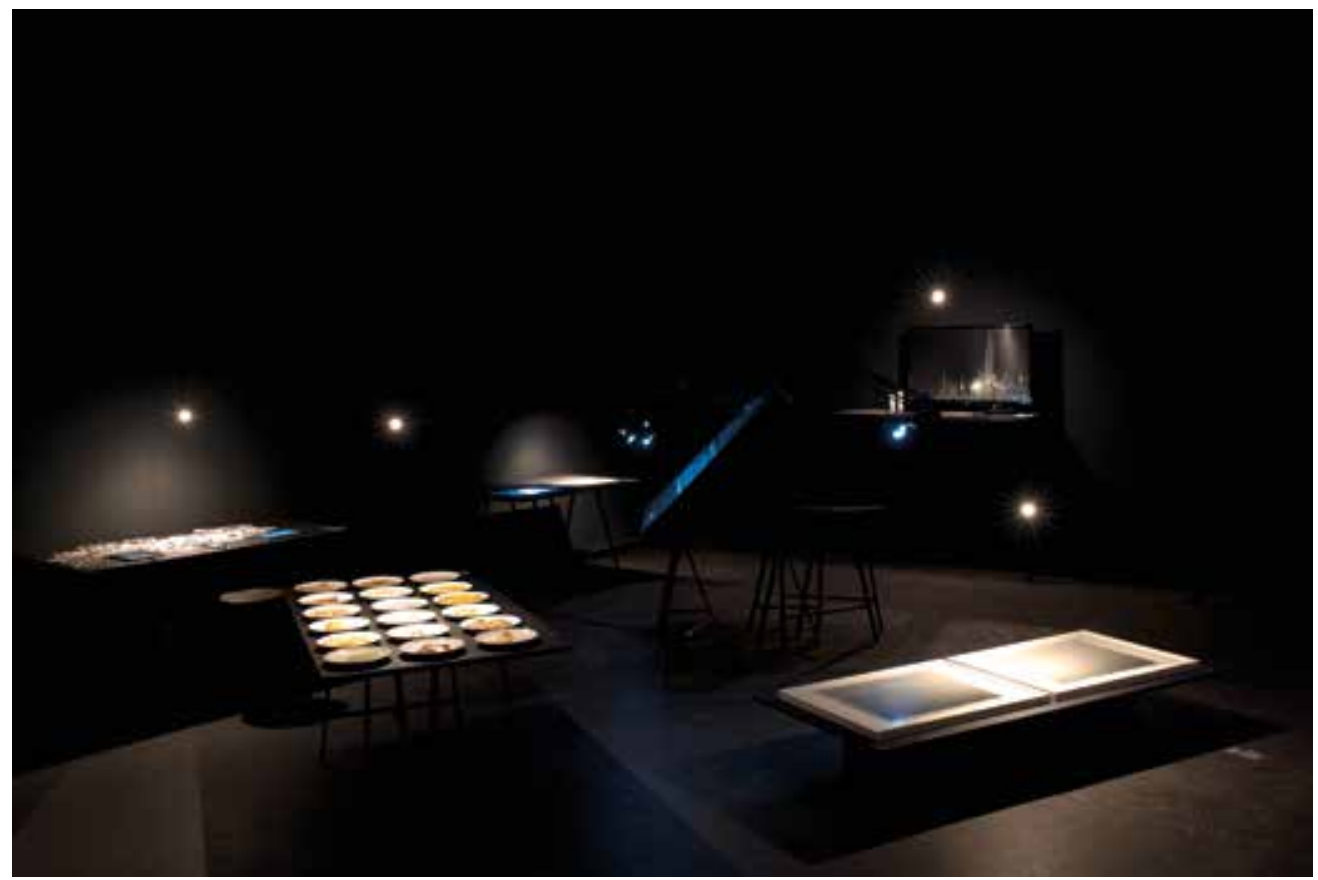

Photo by Fee Hollmig, UdK Berlin, Class Ai

As the audiences entered Room 91, the studio space allocated to the students of Prof. Ai Weiwei, they found themselves in a transformed space, which broke off connection to the hallways crowded by the diverse visitors of the annual Rundgang. The exhibition space no longer showed resemblance to one of the familiar bright and spacious, high white ceilinged studios with high windows that the historical main building of the Universität der Künste Berlin is famous for. Instead, the space was painted from top to bottom in pitch black and refashioned to create a rather withdrawn and embracing atmosphere that drew a clear distinction from what was left behind the heavy black drapes that hung covering the studio's door.

Despite the heat of the summer days that had merged with the unaccounted and uncomfortable humidity in the room, the exhibition succeeded to attract the many curious audiences that were lined up outdoors behind

* Universität der Künste Berlin (UdK Berlin), Class Ai 
the curtains waiting to see the unexpected. Spectators carefully oriented themselves through the exhibition with the help of soft light bulbs that were focused purposely above each project. Each project was represented on identical tables that were in some cases restructured to highlight a project's individual characteristic. The conscious choices taken as part of the curation attempted to form a visual unity and transmit a common feeling that fit the general practice of the one-year long research projects that were mostly developed on theoretical foundations and practical applications that had concentrated from the very beginning on different methods of research.

The dense dark ambiance captured the deep essence of the general theme of the exhibition and was harmonized with its contrasting white. The

I ASK YOU, WHAT IS A REFUGEE? AND CAN THEY NTEGRATE? WILL WE PAVE THE WAY? OR ARE WE XENOPHOBIC? TELL ME, ARE REFUGES FOR DECORATION? AND DOES ART FOLLOW TRENDS? IF SO, THEN WHAT ARE WE SUPPOSED TO SEE? OR HOW DO YOU JIDE AN MAEE AND DO MACHIIES ACTUALLY ACT ETHICALLY? ASK YOU. HAVE YOU EVER SEEN BORDERS IN THE AIR? OR WHAT'S BEYOND THE SEA? WHY DO WE STAY? AND WHAT MOVES BEFUGEES? TELL ME, WHAT IS THE TIME? AND WHERE DO WE GO FROMHERE?

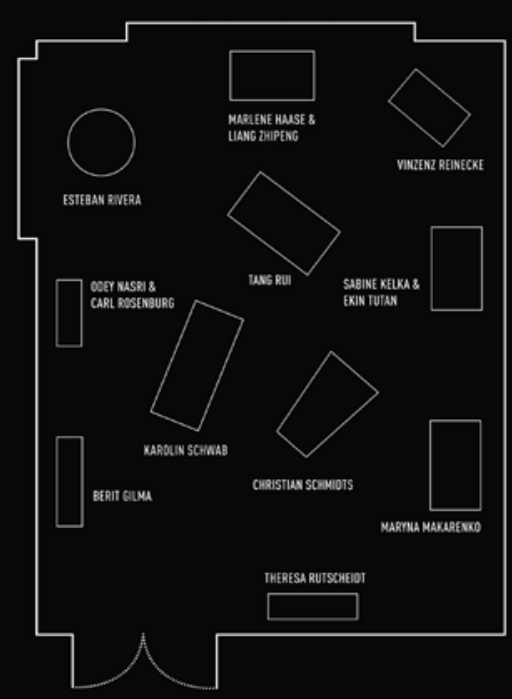

Prof. Ai Weiwei

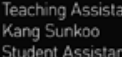

Karolin Schwab

Class Ai

Berit Gwendolyn Gilm

Marlene Haase, Fee

Malmig, Sabine Kelka,
Maryna Makarenko. Vinzer

Reinecke, Esteban Rivera,

Carl Rosenburg. Tang Rui,

Theresa Rutscheidt, Christian

Ekin Tutan, Liang Zhipeng

Exhibition

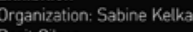

Berit Gilma

Cesign: Sabin

Kelka, Carl Rosenbur

interior Design: Car

Rosentury

Lighting Design: Liang Zhipeng
Flyer

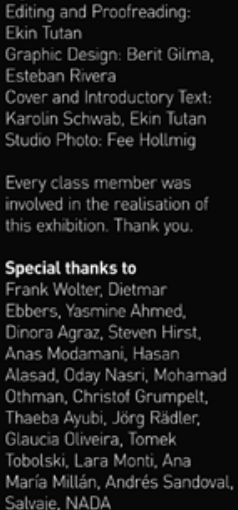

Posters by Berit Gilma, UdK Berlin, Class Ai; text by Karolin Schwab and Ekin Tutan, UdK Berlin, Class Ai 
exhibition's general style concentrated on the juxtaposition of the black and white contrast which was visible from the name tags on the tables, to the enlarged posters hung before the exhibition space, to the hand-size foldable flyers published in conjunction with the exhibition. Imprinted on the flyer's cover page were fifteen questions in white font that were edited into a poetic and complementary flow that stood out dauntlessly on the black surface. They referenced and brought to light the different contexts of the research projects that each student was separately confronted with over the course of the study. Each of the fifteen questions were then hung separately as individual posters around the university corridors for the purpose of evoking audience curiosity and leading them to the exhibition space.

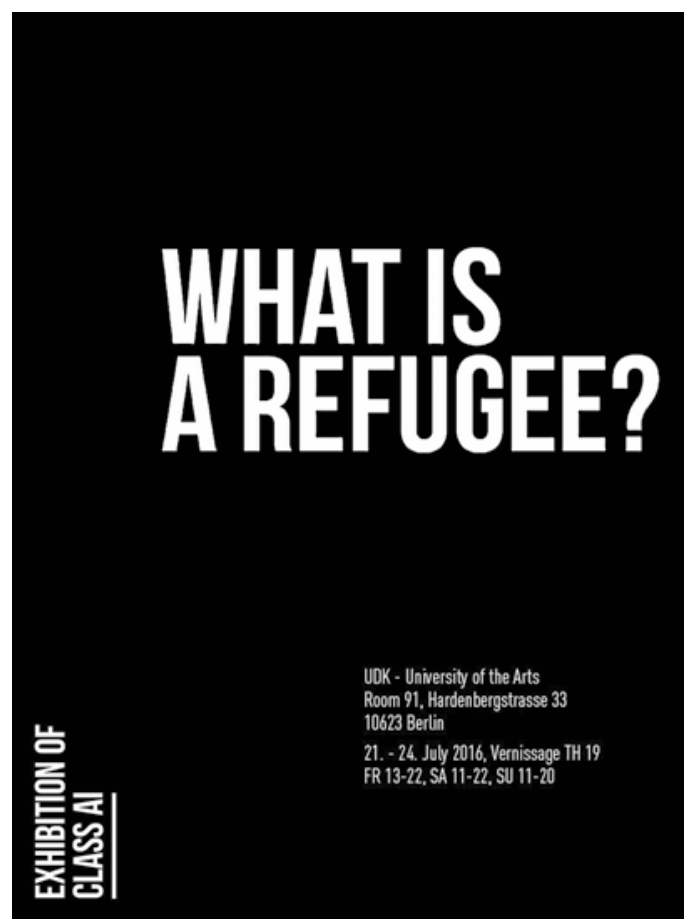

Poster Design by Berit Gilma, UdK Berlin, Class Ai

The topic of "refugees" that has undeniably become a concern and interest for different agents both in the practical and theoretical fields, was the general theme focused on by Class Ai. The students of Prof. Ai Weiwei came to a common decision to reflect on this controversial topic and express their thoughts from their personal and collective standpoints combined with their interdisciplinary and different artistic backgrounds. These reflections came out in the form of eleven visual representations that aimed to convey their understandings and meanings that had been grasped during their research on the topic of refugees and were developed as individual or group research 
projects that both combined and deployed subjective and objective viewpoints. They didn't grow out of a necessity of aiming to verify or promote any specific opinion and perspective, but rather they were formulated out of an accumulation of evidence that grew from personal curiosity.

The students of Class Ai concerned themselves with both past and present events when thinking about and around the notion of refugees and also what it means to be a refugee. Several notions came to mind, but some were in forefront. Refuge, migration, integration, xenophobia, transitions, communication, media and technology, representation and identity were some of the themes in the exhibition. Although some projects had parallel themes, each was distinct from one another, and therefore raised different questions and respectively different answers to what the topic refugees meant to the contributing artists and respectively to the viewers. What is named as research projects can be seen as a process that developed in a timeframe of two academic semesters (2015-2016) where some projects were more specific than others and intended to finish in the course of a year and some had intended to be a part of a longer process that were to develop in the upcoming semesters.

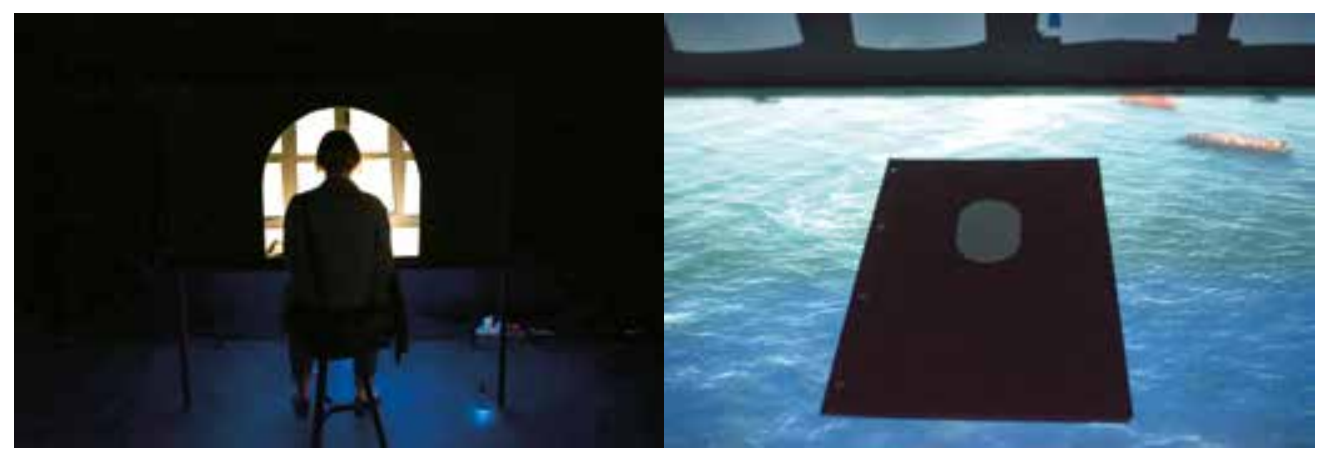

Photo by Fee Hollmig, UdK Berlin, Class Ai

From literal to figurative ways of thinking, the contrast of black and white can be thought of as a metaphor of covering and then uncovering the two-sided approach to the refugee crisis which escalated in the last quarter of the year 2015. The refugee crisis was shifting between two opposing perspectives that were either white or black, pro or anti, welcoming or unwelcoming. At this time, in which the politics of refugees were continually and drastically alternating, several thoughts were resonating through the different voices of the Class Ai members. In addition to thought-provoking discussions, they started wondering who these "others" were that were flooding in masses through the Mediterranean and migrating to Europe, and where and what they were coming from, and by which means?

Not every project dealt directly with current issues in respect to the local/global refugee crisis or the European migrant crisis. However, either 
exploring a historical event or a present happening, the contributing artists observed, analyzed and reflected on the topic of refugees from their personal and present standpoints where one could draw out connections to the scope of the refugee movement and the crisis today. The topic of refugees has a long history. But what makes refugees different today and different in the framework of today's contexts and resources? Today's refugees are different because they transcend boundaries not only physically but also mentally, even before relocation.

Transportation and communication were an important part of the refugee movement and their different means and channels caused changes in the mobilization of individuals. Four projects focused on transportation and boundaries in the framework of transcending boundaries by the means of transportation. Transportation among the refugee crisis is accompanied by the words "smugglers," "refugee boats," "smartphones," "social messengers," and "social network sites". Unfortunately, transportation managed to stay short in the refugee movement as it happened by the means of overloaded refugee boats and under unsafe conditions, which became the general knowledge after confrontation of regular news reports on the upsetting situations. On the other hand, information and communication technology escalated the refugee movement as it enforced individuals to move around the globe.

Karolin Schwab's interest was in earlier human migration. Schwab's research concentrated on the GDR citizens that attempted escape by crossing the Baltic Sea between 1961 and 1989 by non-stop swimming. The research reflected on the present agenda of the refugee movement in the light of an historical happening. The research was presented in the form of two framed images, departure (left) and arrival (right), under the title "Greyzone".

While Schwab kept the focus in and beyond the sea, Liang Zhipeng and Marlene Haase changed the focus of perspective from the sea to the sky. In the framework of the current European migrant crisis, Zhipeng and Haase asked the critical question of "Why Refugees Don't Fly." They researched into political and bureaucratic fields and searched for individuals they could

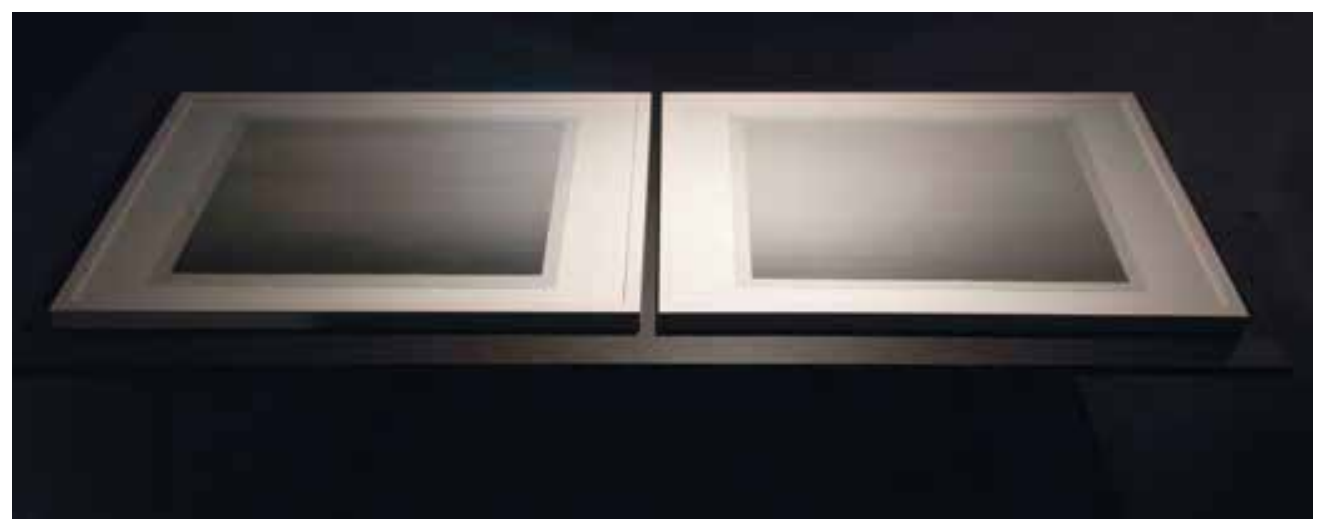

Photo by Fee Hollmig, UdK Berlin, Class Ai 
interview in order to gather information and evidence. They researched visa regulations and procedures of how refugees can enter into Schengen areas by the means of flying in airplanes and respectively into the policies of airline companies. Their research project was presented in the form of an

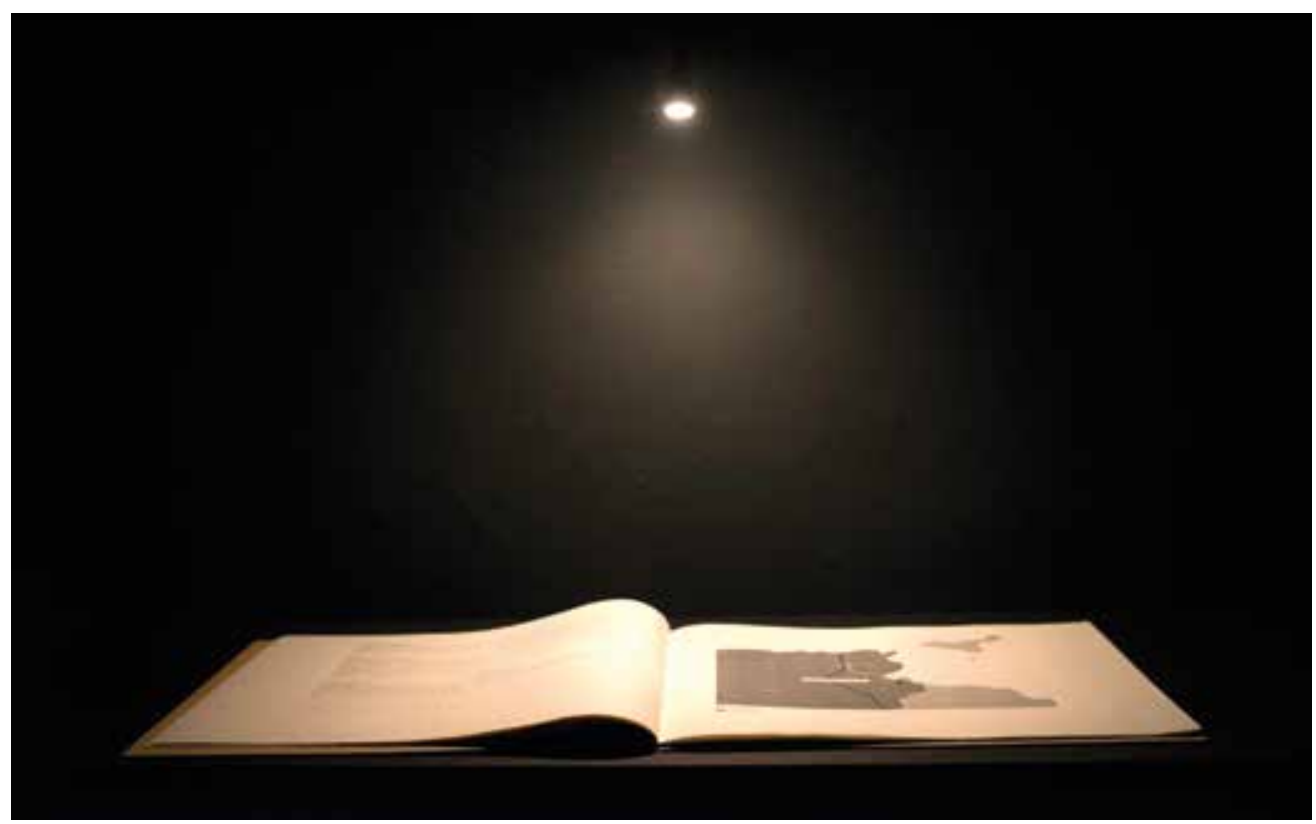

Photo by Fee Hollmig, UdK Berlin, Class Ai

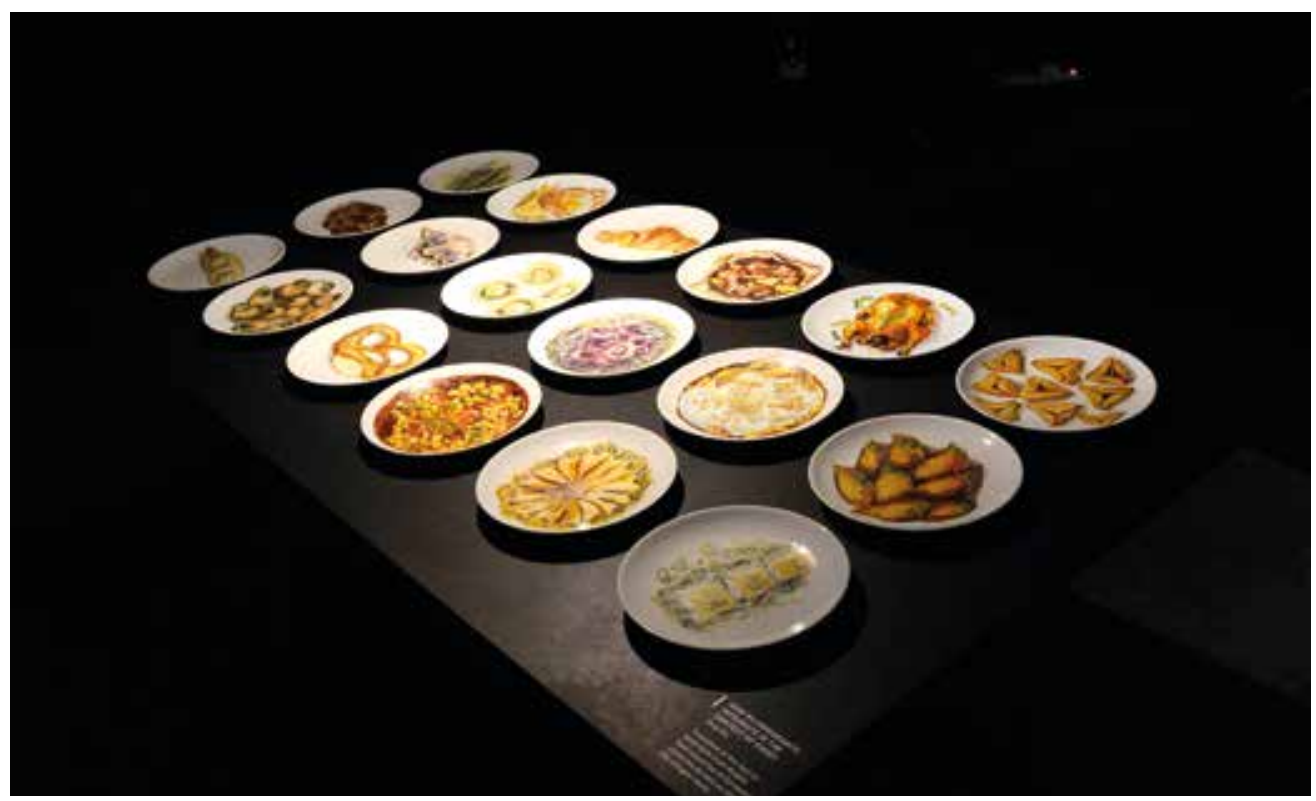

Photo by Fee Hollmig, UdK Berlin, Class Ai 
installation where the audience entered half of their top body into the "Personal Informat" and went through their gathered research notes that were turned into simple booklets, while looking at the Mediterranean Sea from above.

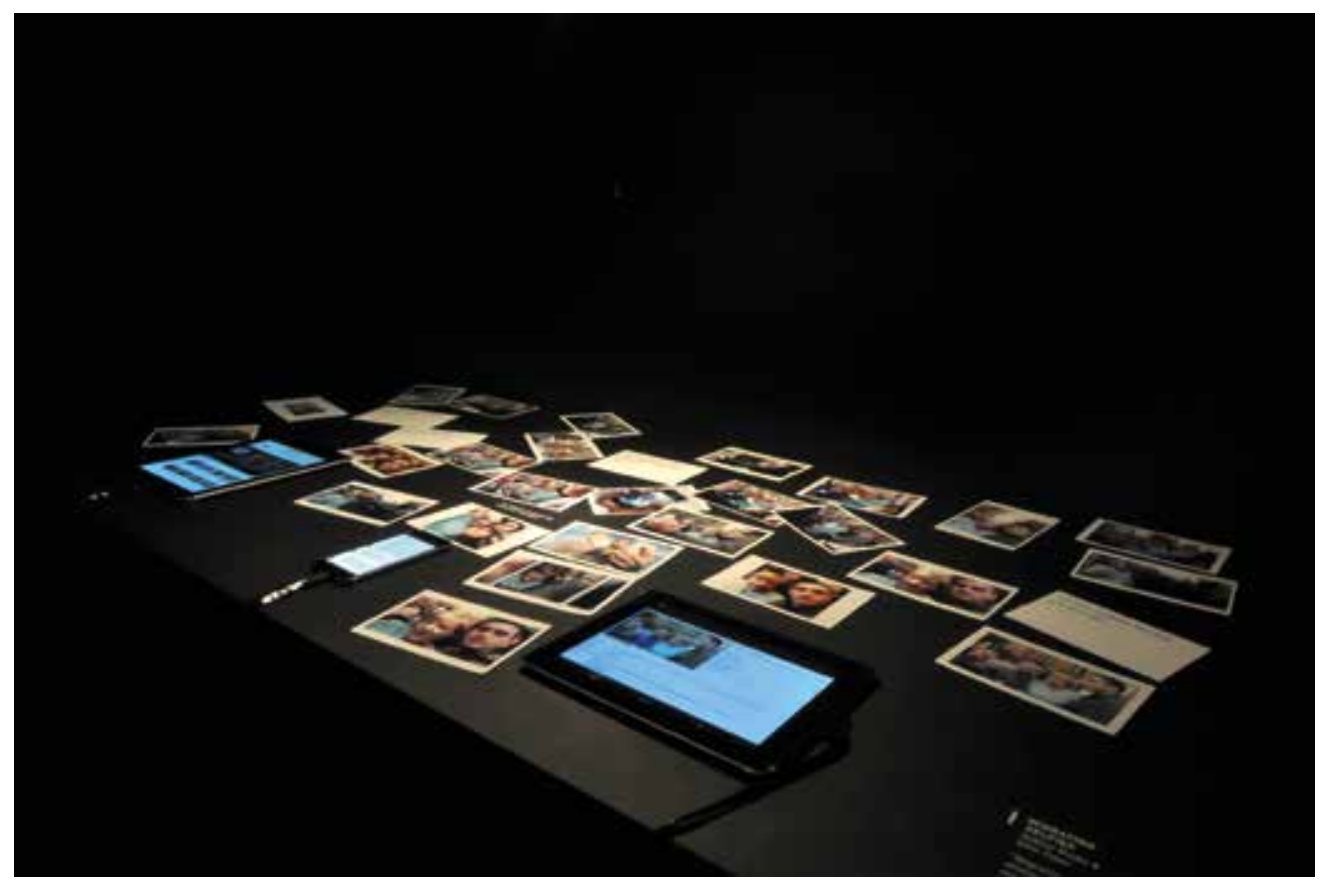

Photo by Christian Schmidts, UdK Berlin, Class Ai

Carl Rosenburg and Tang Rui's projects yet again shifts perspective as they focus on a vast journey that includes water, air and land. Rosenburg and Oday Nasri, who is officially recognised as a refugee, came together to visually document Nasri's journey from Syria to Germany with the help of Nasri's gathered notes, memories, and old tickets. Tang, on the other hand, focuses on transportation and migration in the light of the non-human agent. He looks at the theme of refugees in the framework of direct and indirect migration and integration through cultural and ethnic foods. Tang laid out eighteen plates with hand painted replicas of foods from different regions and lands, which portrays a visual feast of different cultures and meanwhile triggers notions of food as cultural heritage.

Media, communication, and technology are also themes that stand out in the exhibition and connect to transportation and migration. Four groups have researched into this area. Three groups have dealt with the representation of refugees in the media, either visually, verbally or both, and the fourth project was concerned with new technologies.

Media became an essential part of the realization of the refugee movement. It became a source of knowledge and information, and also a medium 


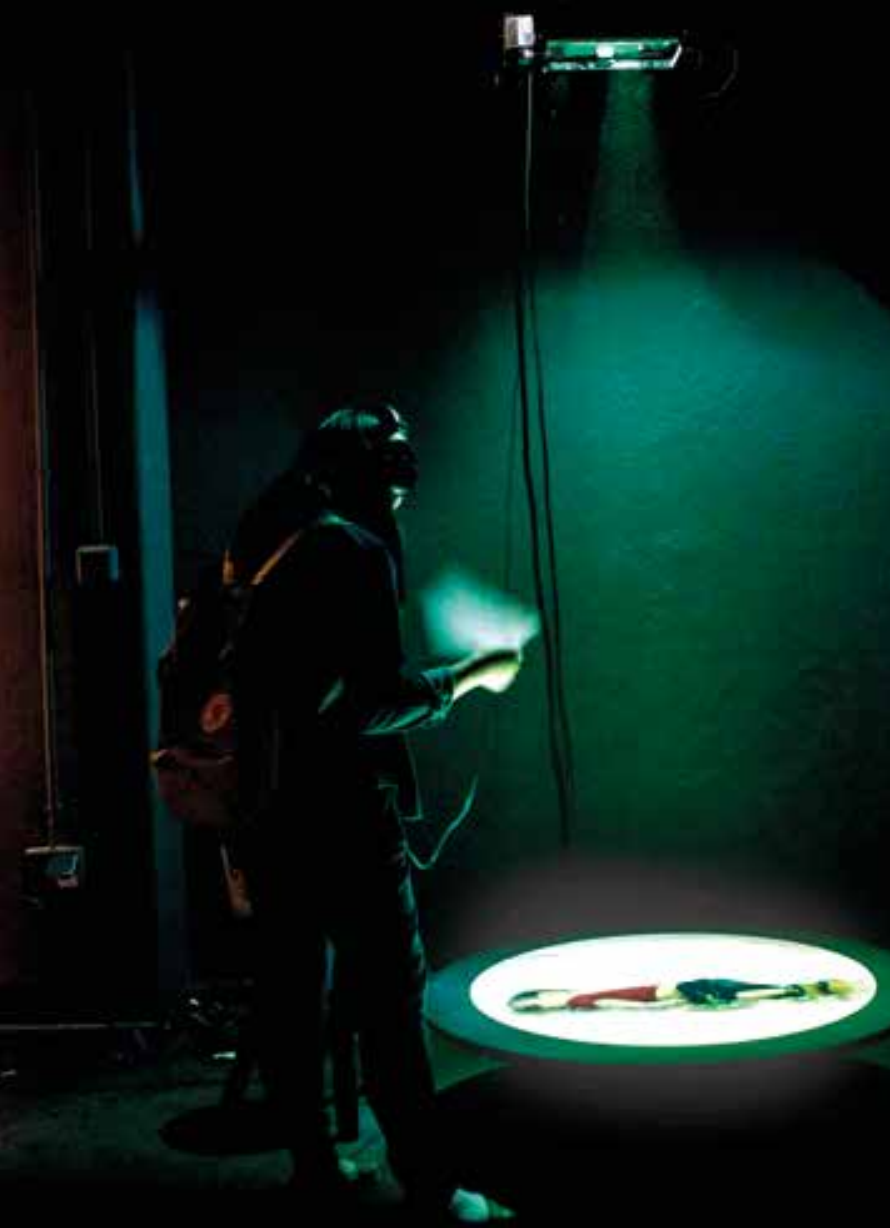


for sharing. Tools like personal smartphones, digital mediums like social media and social networking sites enabled fast distribution of information, and they also became instruments for refugees to organize and act out their movement. All of these enabled not only the mobilization of the individual-person, but also the topic of refugees to transverse different nation-states and different cultures. One was confronted with a diversity of information and perspectives coming from different sources. The production, distribution, and circulation of information opened a window to parallel realities.

Sabine Kelka's and Ekin Tutan's "Migrating Selfies" derives from the metaphor of parallel realities as they try to portray the diverse perceptions caused after a media event. Their main interest lies in capturing a sense of how refugees are visually represented by different channels of media, and within this framework, they focus on the still-image as their medium. They traced and then collected iconic photos of selfies of a few refugees that were lucky to have captured a shot with the German chancellor Angela Merkel. They curated the data as well as the interviews they held with two of the refugees who became household faces into a contemporary digital archive. The photos and original selfies that had circulated widely across the web and that quickly went viral were divided into three channels of reporting, which allowed the viewers to discover the three different types of reporting perspectives on the event.

Esteban Rivera's "Forensics of an Image" focuses on the images produced around Aylan Kurdi's death. Rivera dissects Aylan Kurdi's image by investigating the evidence he has collected such as testimonies of officers, witnesses, and photographers. He explores how Western media is affected by the image by viewing it in relation to other images as an investigation strategy. The work was presented in video form and reflected on a circular table that was meant to symbolize the Pepsi logo.

Theresa Rutscheidt, on the other hand, focuses on the verbal aspect of representation. Rutscheidt's interest lies in the tone of the media. She tracks the tone in which the topic of refugees was discussed in the 365 Edition of the German news service Tagesschau throughout 2015.

Berit Gilma, who takes a different perspective on the focus of media and technology, concentrates on how new technologies that were invented for the surveillance, tracking, and identifying the "other" can determine a refugee's fate. Gilma investigates two moments in time in which she tries to understand how technology correlates with times of war and minority groups.

Integration was also a strong theme of the exhibition. Christian Schmidts's and Maryna Makarenko's projects both show an interest in German immigration processes that lie around "the other". Their approaches to the topic are however distinctive. Schmidts researches in depth into xenophobia and prejudice, and he creates a multi-channel sound installation of a synthesis of forces which oppose immigration. The form of the project gives the impression as if it were purposely made to look like a monster like sculpture used as a metaphor and imitation of society. 


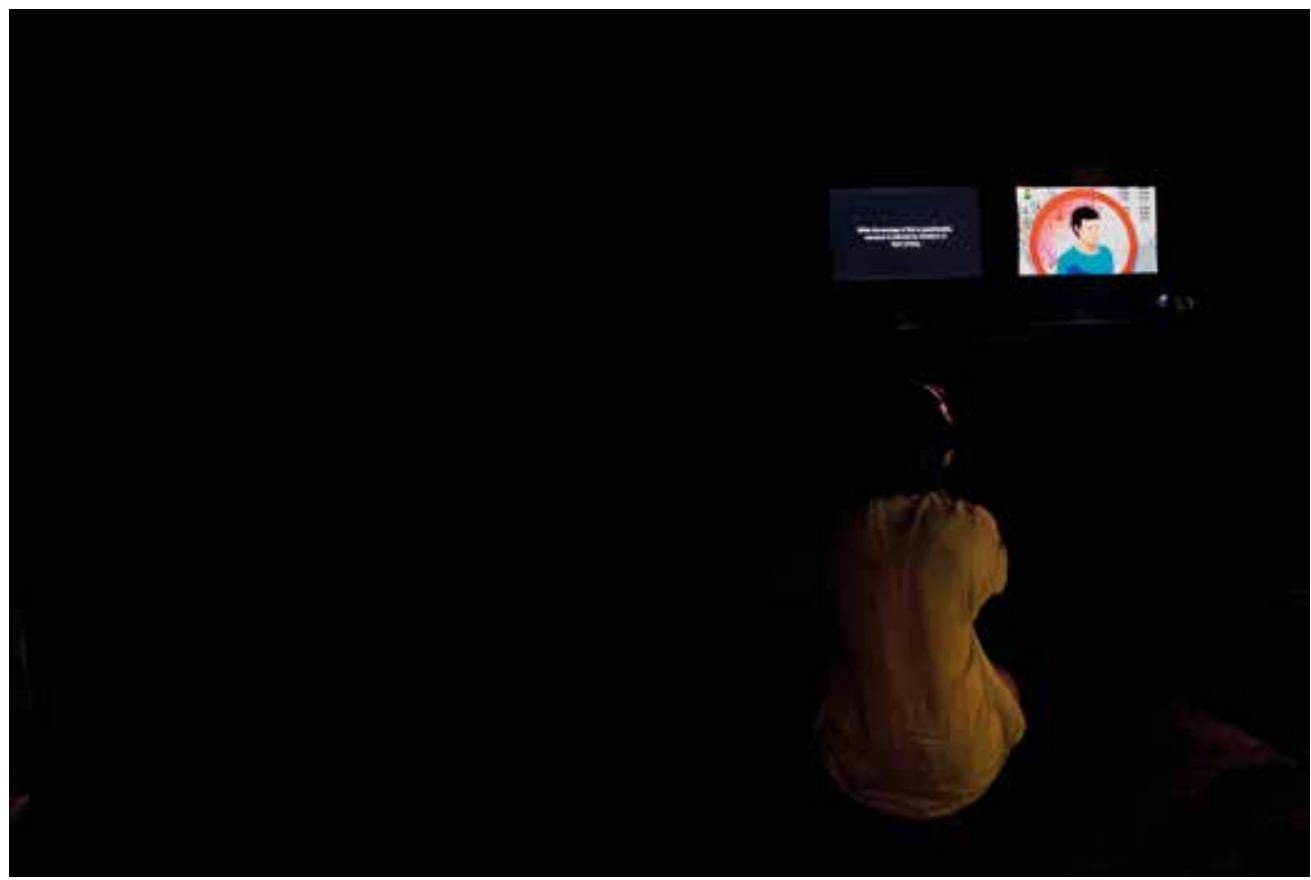

Photo by Fee Hollmig, UdK Berlin, Class Ai

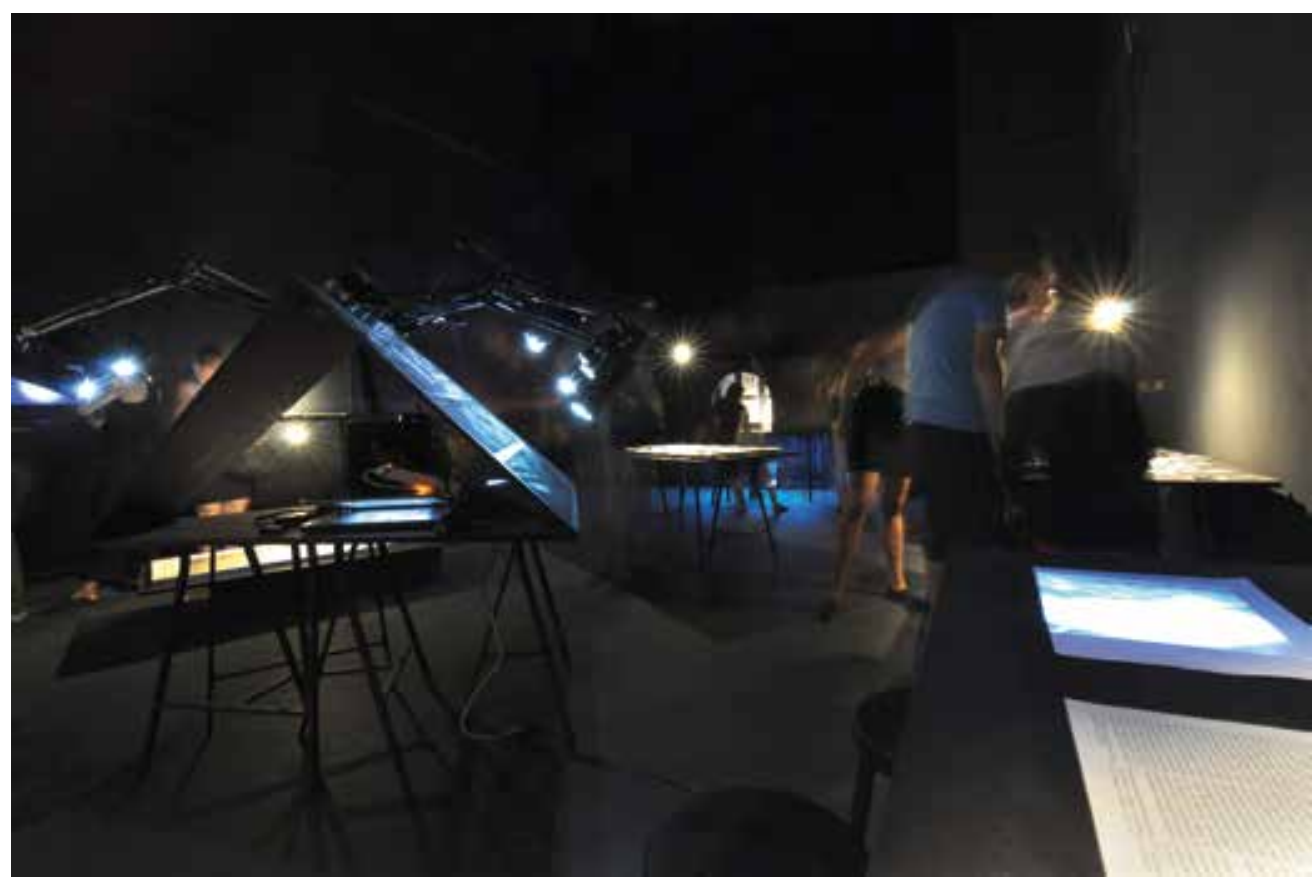

Photo by Christian Schmidts, UdK Berlin, Class Ai 
Makarenko's interest, on the other hand, lies in an individual's behavioral patterns based on expectations of the host society. The work is presented in a visual form where parallels are drawn from the depiction of "the other" in cinema, and on individual's external identity construction of the other.

Last but not least, Vinzenz Reinecke redirects the question of what the topic refugees means to different individuals and audiences as he asks them to note the first five words that come to mind when they think of refugees. His work is presented as a collection of their answers in handwritten form which almost gives the feeling of a mind map in its most raw form.

The exhibition video can be viewed at https://vimeo.com/177361359

Exhibition Organization Sabine Kelka, Berit Gilma Exhibition Design Sabine Kelka, Carl Rosenburg Interior Design Carl Rosenburg Lighting Design Liang Zhipeng Flyer Editing and Proofreading Ekin Tutan Graphic Design Berit Gilma, Esteban Rivera Cover and Introductory Text Karolin Schwab, Ekin Tutan Studio Photo Fee Holming

UdK Berlin, Class Ai, 2015-2016 Berit Gwendolyn Gilma, Marlene Haase, Fee Hollmig, Sabine Kelka, Maryna Makarenko, Vinzenz Reinecke, Esteban Rivera, Carl Rosenburg, Tang Rui, Theresa Rutscheidt, Christian Schmidts, Karolin Schwab, Ekin Tutan, Liang Zhipeng 